\title{
Low-level Laser Therapy Effects on Pulp Cells from Human Primary Teeth
}

\author{
${ }^{1}$ Ana P Fernandes, ${ }^{2}$ Vivien T Sakai, ${ }^{3}$ Bella LC Ishikiriama, ${ }^{4}$ Fernanda V Oliveira, ${ }^{5}$ Natalino Lourenço Neto, \\ ${ }^{6}$ Carlos F Santos, ${ }^{7}$ Maria AAM Machado, ${ }^{8}$ Thais M Oliveira
}

\begin{abstract}
The aim of this study was to verify the influence of different energy densities of low-level laser therapy (LLLT) on the viability and proliferation of pulp fibroblasts of human primary teeth (HPF). Cultures of fibroblast were irradiated with LLLT according to experimental groups: I $\left(1.2 \mathrm{~J} / \mathrm{cm}^{2}\right)$, II $\left(2.5 \mathrm{~J} / \mathrm{cm}^{2}\right)$, III $(3.7$ $\left.\mathrm{J} / \mathrm{cm}^{2}\right)$, IV $\left(5.0 \mathrm{~J} / \mathrm{cm}^{2}\right), \mathrm{V}\left(6.2 \mathrm{~J} / \mathrm{cm}^{2}\right)$, and VI (not irradiated). Cell viability was determined 6 and 24 hours after of irradiation using 3-(4, 5-dimethyl-2-thiazolyl) -2, 5-diphenyl -2H- tetrazolium bromide (MTT) assay. Cell proliferation was assessed through sulforhodamine B (SRB) assay after 24, 48, and 72 hours of irradiation. Data were submitted to two-way analysis of variance (ANOVA) and Tukey test $(p<0.05)$. After 6 hours of irradiation, group III exhibited the greatest cell viability compared with other groups. After 24 hours, group I exhibited the smallest absorbance value compared with group VI. To cell proliferation, 24 and 48 hours after irradiation, all groups showed similar results to those of group VI. After 72 hours, group I showed lower cell proliferation than the others. Group V exhibited results very similar to those of group VI. This study suggests that different energy densities of LLLT influenced the viability and proliferation of HPF.
\end{abstract}

Keywords: Cell culture techniques, Cell proliferation, Fibroblats, Laser therapy.

How to cite this article: Fernandes AP, Sakai VT, Ishikiriama BLC, Oliveira FV, Neto NL, Santos CF, Machado MAAM, Oliveira TM. Low-level Laser Therapy Effects on Pulp Cells from Human Primary Teeth. Int J Laser Dent 2015;5(2):33-37.

Source of support: Nil

Conflict of interest: None

\section{INTRODUCTION}

Recent studies have searched therapeutic alternatives to conventional treatments in order to reestablish the pulp

\footnotetext{
1,4,5 PhD student, ${ }^{2,3,6-8} \mathrm{Phd}$ and Professor

1,4,5,7,8 Department of Pediatric Dentistry, Orthodontics and Public Health, Bauru School of Dentistry, University of São Paulo Bauru, São Paulo, Brazil

${ }^{2}$ Department of Clinics and Surgery, Federal University of Alfenas, Alfenas, Minas Gerais, Brazil

${ }^{3}$ Department of Periodontology, University of the Sacred Heart Bauru, São Paulo, Brazil

${ }^{6}$ Department of Biology Science, Bauru School of Dentistry University of São Paulo, Bauru, São Paulo, Brazil

Corresponding Author: Thais M Oliveira, PhD and Professor Department of Pediatric Dentistry, Orthodontics and Public Health, Bauru School of Dentistry, University of São Paulo Bauru, São Paulo, Brazil, Phone: +551432358224 , e-mail: marchini@usp.br
}

health. ${ }^{1-3}$ One of these alternatives is based on the application of low-level laser therapy (LLLT) on pulp tissue. ${ }^{3,4}$

In vitro and in vivo studies have demonstrated that LLLT may accelerate proliferation of fibroblasts and differentiation of osteoblasts during the processes of bone regeneration and neoformation. Histopathological studies have been conducted on dental pulp aiming at evaluating LLLT effects on both the inflammatory process and the production of extracellular matrix proteins. ${ }^{5,6}$ These extracellular matrix proteins play an important role in the formation of mineralized tissues; are capable of acting on cell differentiation, migration, and proliferation during many stages of dentinogenesis and healing process; and are of fundamental importance in the repair process of pulp tissue. The biostimulation achieved by LLLT depends on the laser irradiation parameters, such as wavelength, output power, and energy density. ${ }^{7-10}$ Several parameters have been used aiming to induce cell proliferation in vitro. ${ }^{11-13}$ The application of similar parameters may cause different effects on cultured cells. Parameters that effectively improve cell growth may increase the protein synthesis. ${ }^{8,13-15}$ Accordingly, it is mandatory that one knows the proper combination of these parameters to achieve the desired effects in pulp therapy.

Energy density may be important to improve cell growth ${ }^{16}$ Notwithstanding, the effect of this parameter range is still unknown, mainly on cells from pulp tissue of human primary teeth. Some studies with pulp tissue cells have shown that different LLLTs, employed with different wavelengths and doses, act increasing the proliferation capacity in vitro 78,17 and stimulating both the structural protein synthesis ${ }^{8,14}$ and the production of growth factors. ${ }^{18}$ However, little evidence has demonstrated that LLLT directly influences on pulp tissue recovery of human primary teeth. Thus, the aim of this study was to verify the influence of different energy densities of LLLT on the viability and proliferation of fibroblasts of human primary teeth.

\section{MATERIALS AND METHODS}

\section{Primary Culture of Dental Pulp}

Ethical approval was obtained from the Institutional Review Board (process \#138.192). Prior to experiments, 


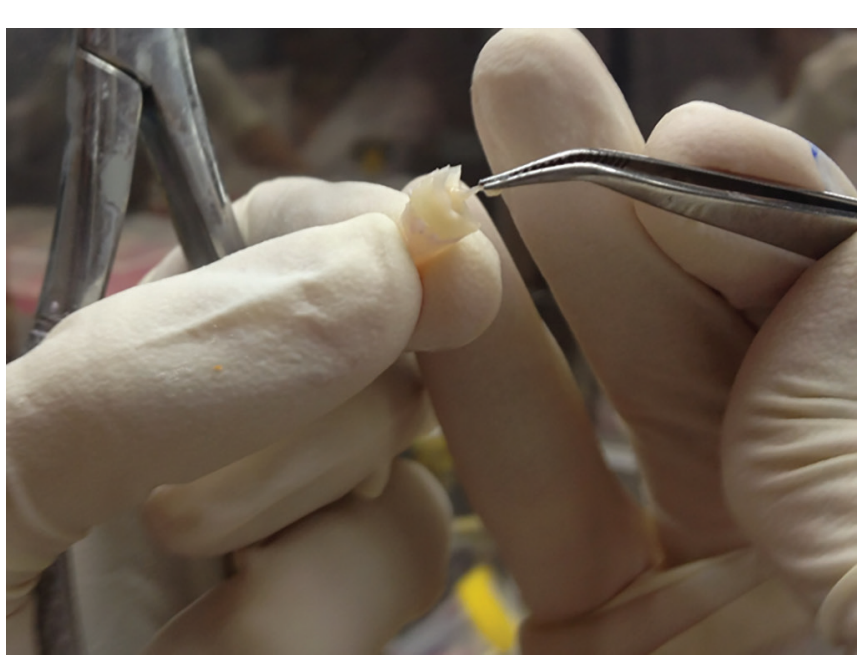

Fig. 1: Deciduous tooth pulp tissue being removed aseptically

the tooth was donated under patient's consent. Dental pulp fibroblasts from human primary teeth were cultured using an explant technique as described previously. ${ }^{19,20}$ The pulp tissues were removed in aseptic conditions (Fig. 1), and after minced, the fragments were incubated for cell growth Dulbecco's Modified Eagle's Medium (DMEM) (Gibco, Invitrogen Corporation, Carlsbad, CA, USA) supplemented with $10 \%$ fetal bovine serum (FBS; Gibco) and antibiotics (100 $\mu \mathrm{g} / \mathrm{mL}$ penicillin, $100 \mu \mathrm{g} / \mathrm{mL}$ streptomycin, and $0.5 \mathrm{mg} / \mathrm{mL}$ amphotericin B - Invitrogen Corporation, Carlsbad, CA, USA). Cultures were maintained at $37^{\circ} \mathrm{C}$ in a humidified atmosphere of $5 \% \mathrm{CO}_{2}$ and $95 \%$ air. Cells were used between the 4 th and 10th passages (Fig. 2).

\section{Experimental Groups}

The groups were divided into six groups according to the energy density of irradiation with LLLT, as described in Table 1.

\section{Low-level Laser Therapy Irradiation}

Dental pulp fibroblasts from human primary teeth were seeded in 96-well plates $\left(1 \times 10^{4}\right.$ cells/well $)$ with DMEM supplemented with $1 \%$ FBS and allowed to attach overnight.

Prior to laser irradiation, the plates were wrapped in a mask made out of black cardboard with holes located

Table 1: Variation of the energy density depending on the power

\begin{tabular}{llll}
\hline Groups & Energy density $\left(\mathrm{J} / \mathrm{cm}^{2}\right)$ & Power $(\mathrm{mW})$ & Time $(\mathrm{sec})$ \\
\hline I & 1.2 & 05 & 10 \\
II & 2.5 & 10 & 10 \\
III & 3.7 & 15 & 10 \\
IV & 5.0 & 20 & 10 \\
V & 6.2 & 25 & 10 \\
VI & No irradiation & - & - \\
\hline
\end{tabular}



Fig. 2: Inverted microscope image of fibroblasts deciduous teeth

in the position of the wells of the experimental groups. Each hole was individually sealed by a hatch, as well as in black cardboard that allowed only the bore of the well that was being irradiated to remain open, while all the others were kept in the dark. ${ }^{21}$ Low-level laser therapy irradiation was made through the transparent bottom of the 96-well plates, keeping the distance between the light beam and the cell monolayer constant at $1 \mathrm{~mm}$. Therefore, the radiation passed directly to the cell monolayer via the plate base without traveling through the culture medium reaching the cells, following the methodology adopted previously. ${ }^{21-23}$ The power of the laser was measured with the Lasercheck Power Meter (Coherent Inc., Santa Clara, California) prior to each application.

Laser irradiation was delivered with galliumaluminum-arsenide (GaAIAs) low-level laser (Twin Flex Evolution MMOptics ${ }^{\circledR}$, São Carlos, Brazil) in all groups in contact, using the punctual irradiation mode at wavelength of $660 \mathrm{~nm}$ (red), output beam area of $0.04 \mathrm{~cm}^{2}$, and varying the energy density in function of the power used for each experimental group. The control group was treated under identical conditions except that the laser device was kept off. After irradiation, the media of all wells were replaced by fresh culture medium supplemented with $10 \%$ FBS.

\section{Analysis of Cell Viability by 3-(4, 5-Dimethyl-2- Thiazolyl)-2, 5-Diphenyltetrazolium Bromide}

Aiming to evaluate the cytotoxicity of the different LLLT irradiation densities, 3-(4, 5-dimethyl-2-thiazolyl)-2, 5-diphenyltetrazolium bromide (MTT) assay was performed 6 and 24 hours after irradiation, and this test consists in the cellular proliferation assay which quantifies the ability of viable cells to reduce a yellow tetrazolium salt to purple formazan crystals by using a mitochondrial enzyme succinate dehydrogenase. For this reason, 
a shorter trial period was chose, in order to verify the different laser doses that could cause death in cells after irradiation. At the end of the respective incubation time, the supernatants were discarded and $200 \mu \mathrm{L}$ MTT solution was added into each well to a final concentration of $5 \mathrm{mg} / \mathrm{mL}$. After an additional 4-hour incubation period, the supernatant was discarded, and $200 \mu \mathrm{L}$ dimethyl sulfoxide (DMSO; Fisher Scientific, Hampton, NH, USA) was added to solubilize the formazan crystals. Immediately, the absorbance was read in a microplate reader (Zenyth, $200 \mathrm{RT}$, Anthos, Cambridge, UK) at $560 \mathrm{~nm}{ }^{24}$ Data were obtained from three wells per condition.

\section{Analysis of Cell Proliferation by Sulforhodamine B}

Cell proliferation by sulforhodamine B (SRB Assay) was assessed after 24, 48, and 72 hours of irradiation. Because this method is based on the principle, which the SRB stains proteins within cells, and it is independent of the metabolic activity, unlike the MTT test, so the period was greater than the MTT assay. At the end of the respective incubation time, cells were fixed by the addition of $10 \%$ trichloroacetic acid and incubated for 1 hour at $4^{\circ} \mathrm{C}$. Plates were washed in tap water five times and allowed to dry. Cellular protein was stained by adding $4 \%$ SRB in $1 \%$ acetic acid and incubated at room temperature for 30 minutes. Excess SRB was removed by washing the wells with $1 \%$ acetic acid, and remaining SRB was solubilized in $10 \mathrm{~mm}$ Tris-base unbuffered. Absorbance was determined on a spectrophotometer at a wavelength of $565 \mathrm{~nm} \cdot{ }^{25,26}$ Data were obtained from three wells per condition.

\section{Statistical Analysis}

Statistical analysis was performed using GraphPad Prism software (GraphPad Prism, San Diego, California, USA). Viability and proliferation data were analyzed by two-way analysis of variance (ANOVA), followed by Tukey's test. Differences were considered significant at $\mathrm{p}<0.05$. Data were expressed as mean value and standard deviation.

\section{RESULTS}

\section{3-(4, 5-dimethyl-2-thiazolyl)-2, 5-diphenyltetrazolium Bromide Assay}

The absorbance rate variations showed statistically significant differences from 6 to 24 hours after irradiation regarding cell viability for all groups.

Six hours after irradiation, statistically significant differences occurred between groups II and III, groups II and VI, and groups III and IV. Group III exhibited the greatest absorbance value compared with those of the other groups at this period.
Twenty-four hours after irradiation, group I showed the lowest absorbance value compared with that of control group (VI), while group IV had the greatest value compared with those of groups I and III (Graph 1).

\section{SBR Assay}

At 24 hours after irradiation, all groups showed cell proliferation similar to that of control group (VI); however, in group I, cell proliferation rate was lower than that of group II, with statistically significant difference.

At 48 hours after irradiation, no statistically significant differences were seen in the cell proliferation among all of the groups $(p>0.05)$.

At 72 hours after irradiation, group I exhibited the lowest cell proliferation than those of the other study groups. Group V showed greater cell proliferation when compared with control group (VI), with no statistically significant difference. Group V exhibited the greatest cell proliferation compared with those of groups I, II, III, and IV, with statistically significant differences $(\mathrm{p}<0.05)($ Graph 2$)$.

\section{DISCUSSION}

Low-level laser therapy has been largely applied in dentistry in order to accelerate the repair process, reduce pain and swelling, and modulate inflammation. Notwithstanding, few studies have investigated the irradiation parameters capable of promoting effects on different cell lines and determining an ideal protocol of irradiation for healing and repair. ${ }^{10}$

In the present study, the metabolic activity of fibroblasts from pulp cells following LLLT application with



Graph 1: Mean cell viability rate (optical density) of human pulp fibroblasts in function of the experimental time after irradiation. Blue column: Optical density after 6 hours. Red column: Optical density after 24 hours. *Statistically significant difference between optical densities 6 hours after irradiation $(p<0.05)$. \#Statistically significant difference between optical densities 24 hours after irradiation $(p<0.05)$ 


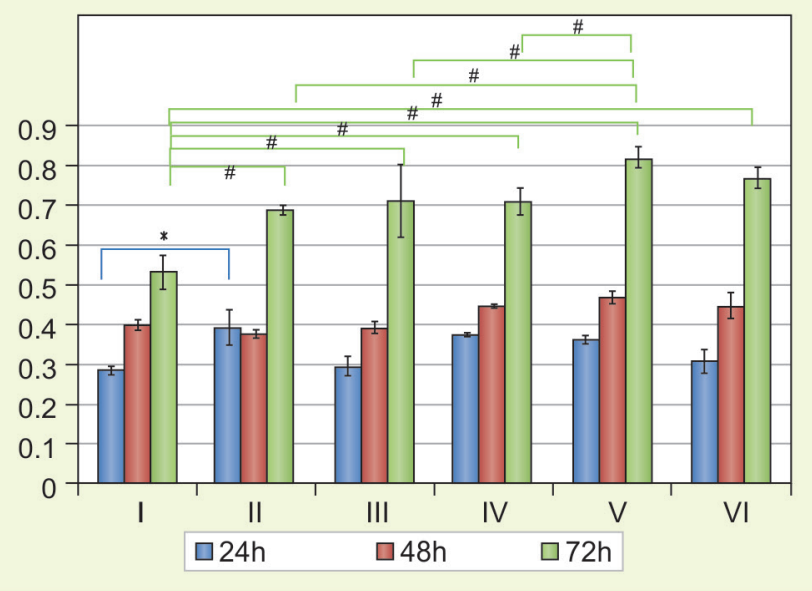

Graph 2: Mean cell proliferation rate (optical density) of human pulp fibroblasts in function of the experimental time after irradiation. Blue column: Optical density after 24 hours. Red column: Optical density after 48 hours. Green column: Optical density after 72 hours. *Statistically significant differences between optical densities 24 hours after irradiation $(p<0.05)$. \#Statistically significant differences between optical densities 72 hours after irradiation $(p<0.05)$

different energy densities in function of the power was evaluated to determine the adequate dosage to produce biomodulation effects on cells in vitro. MTT results demonstrated statistically significant differences for all groups between 6 and 24 hours. Notwithstanding, at 6-hour period, cellular metabolism was greater at $3.7 \mathrm{~J} / \mathrm{cm}^{2}$ dose in comparison with those of the other groups. At 24-hour period, $1.2 \mathrm{~J} / \mathrm{cm}^{2}$ dose exhibited the smallest cellular metabolism in comparison with that of the nonirradiated group (control), while $5.0 \mathrm{~J} / \mathrm{cm}^{2}$ dose presented the greatest value compared with those of 1.2 and $3.7 \mathrm{~J} / \mathrm{cm}^{2}$ doses. The increase in cell metabolism after LLLT irradiation was observed previously, although the cells used in those studies were fibroblast from gingival tissue. ${ }^{10,15}$ The present study observed a different behavior at 6 and 24 hours, at the different irradiation patterns. However, it was not possible to affirm which parameter would be ideal. Considering the cell proliferation after 24 and 48 hours of irradiation, all groups exhibited results similar to those of the group without irradiation (control group). After 72 hours, the cell proliferation irradiated at $1.2 \mathrm{~J} / \mathrm{cm}^{2}$ dose (group I) was smaller than those of all other groups. At $6.2 \mathrm{~J} / \mathrm{cm}^{2}$ dose, there was a greater cell proliferation rate than those of 1.2 to $5.0 \mathrm{~J} / \mathrm{cm}^{2}$ doses, but very similar to that of the group without irradiation (control group). Other studies have also confirmed that LLLT stimulates the presence of photoreceptors within cellular membrane, which increases cell functions and cell proliferation. ${ }^{13}$ It is worth emphasizing that most of the studies in literature have been conducted on fibroblasts from gingival tissue instead of fibroblasts from dental pulp of human primary teeth as in this study. The fact of performing primary culture of pulp cells from human primary teeth in vitro raises the possibility of conducting many studies with the proposed methodology.

Many mechanisms are involved in the cellular metabolism during healing and repair processes. Previous studies demonstrated that LLLT may cause positive cellular effects because of the increase of expression and secretion of growth factors, which can be a specific mode of action of laser parameters. ${ }^{10}$

Some authors have observed that LLLT applied on cell culture may increase the proliferation rates of many cell lines and the production of increased adenosine triphosphate (ATP), ribonucleic acid (RNA), and deoxyribonucleic acid (DNA) synthesis in stem cells and other cell types. ${ }^{13}$ Low-level laser therapy have also improved cell proliferation without any cytotoxic effects and its results have varied according to both the energy density applied and the cells used. This evaluation suggests that LLLT energy density of 0.5 to $4.0 \mathrm{~J} / \mathrm{cm}^{2}$ and visible spectrum of 600 to $700 \mathrm{~nm}$ may be very useful in increasing the proliferation rate of many cellular types. ${ }^{13}$ Low-level laser therapy can improve the cell proliferation in cultured cells (including undifferentiated cells), which might be very useful in tissue engineering and regenerative medicine. A study showed that LLLT irradiation with a series of dose parameters may cause significant changes in gene expression and that these effects depend on the wavelength and radiation exposure. ${ }^{12}$ Thus, the authors concluded that laser irradiation is capable of modulating the genetic expression and releasing growth factors and cytokines of culture cells. These authors also emphasized the need of clinical trials to clarify the clinical relevance of LLLT's positive effects. ${ }^{12}$

The present study showed that LLLT biomodulated the metabolism of pulp cells from human primary teeth. Notwithstanding, other in vitro and in vivo parameters need to be tested. The definition of protocols comprising more specific indications regarding to time, doses, and application sites have been expected. ${ }^{27}$ Therefore, further studies are necessary to determine the ideal laser irradiation protocol for pulp cells from human primary teeth by assessing cell growth, viability, migration, and differentiation through different dosimetry parameters.

This study suggests that different energy densities of LLLT had effects on the viability and proliferation of pulp fibroblasts from human primary teeth. However, further studies are necessary to determine the ideal energy density protocol for laser irradiation on pulp cells from human primary teeth. 


\section{ACKNOWLEDGMENT}

The authors would like to acknowledge the financial support of the Sao Paulo Research Foundation (FAPESP grants \# 2011/19062-0 to TMO).

\section{REFERENCES}

1. Tziafas D, Smith AJ, Lesot H. Desining new treatment strategies in vital pulp therapy. J Dent 2000 Feb;28(2):77-92.

2. Martens LC. Laser physics and a review of laser applications in dentistry for children. Eur Arch Paediatr Dent 2011 Apr;12(2):61-67.

3. De Coster P, Rajasekharan S, Martens L. Laser-assisted pulpotomy in primary teeth: a systematic review. Int J Paediatr Dent 2013 Nov;23(6):389-399.

4. Golpayegani MV, Ansari G, Tadayon N. Clinical and radiographic success of Low Level Laser Therapy (LLLT) on primary molars pulpotomy. Res J Biol Sci 2010;5(1):51-55.

5. Utsunomiya T. A histopathological study of the effects of low-power laser irradiation on wound healing of exposed dental pulp tissues in dogs, with special reference to lectins and collagens. J Endod 1998 Mar;24(3):187-193.

6. Ohbayashi E, Matsushima K, Hosoya S, Abiko Y, Yamazaki M. Stimulatory effect of laser irradiation on calcified nodule formation in human dental pulp fibroblastos. J Endod 1999 Jan;25(1):30-33.

7. Almeida-Lopes L, Rigau J, Zângaro RA, Guidugli-Neto J, Jaeger MM. Comparison of the low level laser therapy effects on cultured human gingival fibroblastos proliferation using different irradiance and same fluence. Lasers Surg Med 2001;29(2):179-184.

8. Pereira AN, Eduardo Cde P, Matson E, Marques MM. Effect of low-power laser irradiation on cell growth and procollagen synthesis of cultured fibroblasts. Lasers Surg Med 2002;31(4):263-267.

9. Kreisler M, Christoffers AB, Al-Haj H, Willershausen B, d'Hoedt B. Low level 809-nm diode laser-induced in vitro stimulation of the proliferation of human gingival fibroblasts. Lasers Surg Med 2002;30(5):365-369.

10. Basso FG, Pansani TN, Turrioni AP, Bagnato VS, Hebling J, de Souza Costa CA. In vitro wound healing improvement by low-level laser therapy application in cultured gingival fibroblasts. Int J Dent 2012;2012:719452.

11. Peplow PV, Chung TY, Baxter GD. Laser photobiomodulation of proliferation of cells in culture: a review of human and animal studies. Photomed Laser Surg 2010 Aug;28 (Suppl 1): S3-S40.

12. Peplow PV, Chung TY, Ryan B, Baxter GD. Laser photobiomodulation of gene expression and release of growth factors and cytokines from cells in culture: a review of human and animal studies. Photomed Laser Surg 2011 May;29(5): 285-304.

13. AlGhamdi KM, Kumar A, Moussa NA. Low-level laser therapy: a useful technique for enhancing the proliferation of various cultured cells. Lasers Med Sci 2012 Jan;27(1):237-249.

14. Marques MM, Pereira AN, Fujihara NA, Nogueira FN, Eduardo CP. Effect of low-power laser irradiation on protein synthesis and ultrastructure of human gingival fibroblasts. Lasers Surg Med 2004;34(3):260-265.

15. Damante CA, De Micheli G, Miyagi SP, Feist IS, Marques MM. Effect of laser phototherapy on the release of fibroblast growth factors by human gingival fibroblasts. Lasers Med Sci 2009 Nov;24(6):885-891.

16. Pourzarandian A, Watanabe H, Ruwanpura SM, Aoki A, Ishikawa I. Effect of low-level Er:YAG laser irradiation on cultured human gingival fibroblasts. J Periodontol 2005 Feb;76(2):187-193.

17. Moore P, Ridgway TD, Higbee RG, Howard EW, Lucroy MD. Effect of wavelength on low-intensity laser irradiationstimulated cell proliferation in vitro. Lasers Surg Med 2005 Jan;36(1):8-12.

18. Saygun I, Karacay S, Serdar M, Ural AU, Sencimen M, Kurtis B. Effects of laser irradiation on the release of basic fibroblast growth factor (bFGF), insulin like growth factor-1 (IGF-1), and receptor of IGF-1 (IGFBP3) from gingival fibroblasts. Lasers Med Sci 2008 Apr;23(2):211-215.

19. SipertCR, Moraes IG, BernardinelliN, Garcia RB, BramanteCM, Gasparoto TH, Figueira EA, Dionísio TJ, Campanelli AP, Oliveira SH, et al. Heat-killed Enterococcus faecalis alters nitric oxide and CXCL12 production but not CXCL8 and CCL3 production by cultured human dental pulp fibroblasts. J Endod 2010 Jan;36(1):91-94.

20. Morandini AC, Sipert CR, Gasparoto TH, Greghi SL, Passanezi E, Rezende ML, Sant'ana AP, Campanelli AP, Garlet GP, Santos CF. Differential production of macrophage inflammatory protein-1alpha, stromal-derived factor-1, and IL-6byhumancultured periodontalligamentand gingival fibroblasts challenged with lipopolysaccharide from $P$. gingivalis. J Periodontol 2010 Feb;81(2):310-317.

21. Volpato LE, de Oliveira RC, Espinosa MM, Bagnato VS, Machado MA. Viability of fibroblasts cultured under nutritional stress irradiated with red laser, infrared laser, and red light-emitting diode. J Biomed Opt 2011 Jul;16(7):075004.

22. Azevedo LH, de Paula Eduardo F, Moreira MS, de Paula Eduardo C, Marques MM. Influence of different power densities of LILT on cultured human fibroblast growth: a pilot study. Lasers Med Sci 2006 Jul;21(2):86-89.

23. EduardoFP,MehnertDU,MoneziTA,ZezellDM,SchubertMM, Eduardo CP, Marques MM. Cultured epithelial cells response to phototherapy with low intensity laser. Lasers Surg Med 2007 Apr;39(4):365-372.

24. Cheng CC, Lee YH, Lin SP, Huangfu WC, Liu IH. Cellautonomous heparanase modulates self-renewal and migration in bone marrow-derived mesenchymal stem cells. J Biomed Sci 2014 Mar 13;21(1):21.

25. Keepers YP, Pizao PE, Peters GJ, van Ark-Otte J, Winograd B, Pinedo HM. Comparison of the sulforhodamine B protein and tetrazolium (MTT) assays for in vitro chemosensitivity testing. Eur J Cancer 1991;27(7):897-900.

26. Sakai VT, Zhang Z, Dong Z, Neiva KG, Machado MA, Shi S, Santos CF, Nör JE. SHED differentiate into functional odontoblasts and endothelium. J Dent Res 2010 Aug;89(8):791-796.

27. Caprioglio C, Olivi G, Genovese MD. Lasers in dental traumatology and low level laser therapy (LLLT). Eur Arch Paediatr Dent 2011 Apr;12(2):79-84. 